\title{
Preferências visuais das crianças em salas de aula de educação infantil: uma aproximação experimental
}

\author{
Visual preferences of pre-school children: an \\ experimental approach
}

\section{Natalia Giraldo Vásquez \\ Fernando Oscar Ruttkay Pereira \\ Ariane Kuhnen}

\section{Resumo}

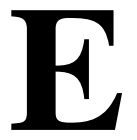

m conforto visual, as pesquisas com crianças têm sido direcionadas ao estudo dos impactos da luz no desempenho acadêmico, e não propriamente na avaliação das preferências, o que evidencia a carência teórica e metodológica nessa linha de estudo. No caso de crianças mais novas, entre 4 e 7 anos de idade, como as habilidades básicas para o intercâmbio verbal estão em desenvolvimento, restringe-se a aplicação de testes escritos. Este artigo, resultado de um trabalho conjunto entre arquitetura e psicologia, apresenta uma abordagem experimental e multimétodos para levantar as preferências do ambiente luminoso, da paisagem e das características de uso de salas de aula de educação infantil. O estudo foi realizado em duas salas de aula do Colégio Logosófico González Pecotche, da cidade de Florianópolis, durante o mês de agosto de 2015. Neste estudo participaram aproximadamente 30 crianças entre 4 e 6 anos de idade. Os resultados obtidos permitem identificar a preferência das crianças por elementos da paisagem natural e por ambientes luminosos mais claros. Foi identificada a relação que as crianças fazem entre as condições de iluminação e as atividades realizadas. Finalmente, a abordagem metodológica se mostra efetiva na aproximação das crianças e na avaliação das preferências com relação ao ambiente luminoso das salas.

Palavras-chave: Mapeamento comportamental. Crianças. Preferências. Iluminação. Salas de aula.

Natalia Giraldo Vásquez Universidade Federal de Santa Catarina

Florianópolis - SC - Brasil

Fernando Oscar Ruttkay Pereira Universidade Federal de Santa
Catarina Florianópolis - SC - Brasil Ariane Kuhnen
Universidade Federal de Santa
Catarina
Florianópolis - SC - Brasil

Recebido em 23/11/17 Aceito em 06/02/18

\begin{abstract}
Within the field of visual comfort, studiess with children have been focused on the study of the impact of lighting on academic performance and not in the assessment of preferences, evidencing the theoretical and methodological lack of this line of study. In the case of younger children, between 4 and 7 years old, the basics skills for verbal communication are still developing, restricting the use of written tests. This paper, a result of a joint work between architecture and psychology, presents an experimental and a multi-method approach to collect the preferences related to the luminous environment, the landscape and the characteristics of use of kindergarten classrooms. The study was conducted in two classrooms of the Colégio Logosófico González Pecotche, in the city of Florianópolis, during August of 2015. Thirty children between 4 and 6 years old participated in this study. The results allowed the identification of the children's preferences for elements of natural landscape and for clearer luminous environments. The relationship they construct between lighting conditions and activities performed was also identified. Finally, the methodological approach was effective in the approximation of the children and the evaluation of preferences regarding the luminous environment of the classrooms.

Keywords: Behavioral mapping. Children. Preferences. Lighting. Classrooms.
\end{abstract}




\section{Introdução}

O interesse de pesquisadores de diversas áreas por conhecer as opiniões das crianças tem aumentado desde início do século XX (CRUZ, 2010). Diferentemente da psicologia, cujos estudos com crianças de todas as idades são comuns, na área de conforto ambiental os estudos com esse tipo de população são raros. A preocupação com a qualidade dos ambientes escolares demanda então o estudo do comportamento, desempenho e preferências de crianças em diferentes faixas etárias. O interesse de alguns pesquisadores sobre as características dos ambientes escolares se dá devido à relação destas com o processo de aprendizado (BARRETT et al., 2015; BLUYSSEN, 2017; HESCHONG..., 2003; TANNER, 2009).

A revisão realizada por Collins (1976), de estudos datados entre 1958 e 1974, buscou identificar a relação entre a atitude de crianças e seu desempenho acadêmico em ambientes com e sem janelas. Em uma época na qual a ausência de janelas nas salas era uma prática comum na arquitetura escolar, o autor identificou a preferência dos alunos por salas de aula com janelas e maior absentismo nas salas de educação infantil sem aberturas. Anos mais tarde, Stewart (1981) provou que as crianças (especialmente entre 9 e 11 anos) sentem-se atraídas pelas janelas e pela luz natural, o que se reflete em seu comportamento. A pesquisa demonstrou que em situações de livre escolha as crianças preferem estar perto das janelas devido à quantidade de luz, à visualização da natureza e à possibilidade de ver o que acontece fora da sala.

Visando entender melhor as formas nas quais o ambiente influencia no progresso de aprendizado das crianças (numa faixa etária de 5 a 11 anos), Barrett e Barrett (2010) propuseram recentemente o modelo Ambiente-Comportamento. Esse modelo estabelece três princípios que facilitam o aprendizado no ambiente construído da escola: a naturalidade, a individualização e o nível de estímulo. Os parâmetros físicos do ambiente (iluminação, temperatura, acústica, qualidade do ar e conexões com a natureza) estão contidos no princípio da naturalidade, o princípio de maior influência no desempenho: até 50\% do desempenho das crianças foi afetado pela iluminação, temperatura e qualidade do ar da sala de aula (BARRETT et al., 2015). Posteriormente foi verificado que a iluminação e a flexibilidade das salas de aula foram os fatores de maior impacto no progresso das crianças (BARRETT et al., 2017). Apesar da relevância dos resultados, apenas alguns desses estudos consideraram crianças no último ano da educação infantil (BARRETT et al., 2015, 2017; BARRETT; BARRETT, 2010).
Perante o desafio metodológico que representa a comunicação entre o adulto pesquisador e a criança, sujeito de estudo, instrumentos e técnicas desenvolvidos e validados na psicologia possibilitam o acesso às opiniões da criança desde sua própria experiência (CRUZ, 2010; SAYWITZ; CAMPARO, 2013; SOUZA, 2010), o que permite superar com sucesso o temor sobre a maneira mais adequada para obter respostas (confiáveis) das crianças. Contudo, aproximar-se da criança requer um esforço por parte do adulto pesquisador para garantir maior confiabilidade nos dados obtidos. O tempo de convívio com a criança é fundamental para estabelecer um vínculo de confiança que permita a ela compartilhar suas experiências e opiniões de forma mais precisa (CRUZ, 2010; SAYWITZ et al., 2015).

A abordagem multimétodos, recomendada nos estudos com crianças de acordo com Morrow (2001), tem sido aplicada em alguns estudos da área de conforto ambiental (BERNARDI; KOWALTOWSKI, 2006; FABBRI, 2013). Entre as técnicas usadas nesses estudos destacam-se a observação direta e a observação indireta, por meio das quais o pesquisador pode definir diferentes graus de interação com os participantes (MARKOPOULOS et al., 2008a; PINHEIRO; ELALI; FERNANDES, 2008). Apoiado nos dados da observação, o mapeamento comportamental é uma técnica que permite associar fenômenos do comportamento das pessoas e o ambiente no qual ocorrem (SOMMER; SOMMER, 2001), o qual é amplamente usado nas pesquisas que envolvem crianças e deriva resultados mais gráficos (PINHEIRO; ELALI; FERNANDES, 2008).

A entrevista é uma outra técnica comumente usada nos estudos com crianças (SAYWITZ; CAMPARO, 2013). Através dela é possível obter respostas precisas, já que as informações podem ser apresentadas de forma verbal ou gráfica, sendo uma técnica de adequada aplicação nos estudos com crianças em idade pré-escolar (MARKOPOULOS et al., 2008b). Saywitz, Larson e Goodman (2011) identificaram que, ao oferecer à criança opções de resposta como "Eu não sei” ou "Eu não entendi”, o desempenho durante a entrevista pode melhorar. Assim mesmo, apresentar a entrevista por meio de atividades mais dinâmicas, tais como jogos, também ajuda a manter o interesse da criança no assunto (BORGERS; HOX; SIKKEL, 2003; BORGERS; LEEUW; HOX, 2000).

Desenhos e fotografias têm sido considerados úteis e adequados em pesquisas com crianças e em pesquisas de avaliação da preferência/qualidade da paisagem. Alguns estudos com crianças que ainda 
não desenvolveram as capacidades de leitura e escrita, isto é, em idade pré-escolar, têm concentrado seus esforços na adaptação da abordagem metodológica para conseguir a avaliação das condições ambientais (FABBRI, 2013; GIRALDO et al., 2014). Os resultados obtidos nessas pesquisas demonstram que, mesmo sendo muito novas, as crianças têm noções dos fenômenos ambientais que afetam sua sensação de conforto e possuem preferências as quais, em algumas ocasiões, só conseguem manifestar quando perguntadas de forma direta.

Mesmo que as técnicas e ferramentas a serem usadas nos estudos com crianças sejam diversas, as pesquisas de conforto ambiental com esses usuários ainda são limitadas. A carência de estudos direcionados à avaliação das preferências do ambiente, de crianças novas, põe em evidência a lacuna teórica e metodológica na área. No caso da avaliação das condições da iluminação natural e preferências visuais, o desafio metodológico é ainda maior devido à rápida e constante variação da luz, assim como à menor sensibilidade de nosso sistema visual às mudanças luminosas.

O objetivo deste artigo é apresentar uma abordagem metodológica experimental que permita a aproximação de crianças entre 4 e 6 anos de idade para identificar as preferências do ambiente luminoso e das paisagens vistas através da janela, e as condições de uso de salas de aula de educação infantil.

\section{Método}

Este estudo foi realizado com a participação de crianças entre 4 e 6 anos de idade em duas salas de educação infantil do Colégio Logosófico Gonzalez Pecotche, unidade de Florianópolis, durante o mês de agosto de 2015. O roteiro das atividades realizadas neste estudo foi definido juntamente com a diretora geral do Colégio. As atividades que envolveram a participação das crianças foram coordenadas com as professoras das duas turmas que participaram do estudo, tendo sido realizadas cinco visitas em cada sala.

A metodologia utilizada envolveu procedimentos experimentais de campo por meio de uma abordagem multimétodos. O uso das salas de aula foi levantado mediante entrevistas com as docentes, e os modelos de ocupação foram levantados utilizando-se a observação e o mapeamento comportamental. A caracterização das condições de iluminação das salas foi realizada de forma paralela à observação usando-se dez fotocélulas conectadas a sistemas de aquisição remota de dados. A avaliação da preferência das crianças pelas condições do ambiente luminoso foi obtida mediante entrevistas individuais. Os dados de preferência pelo tipo de paisagem foram levantados por meio de desenhos realizados por cada uma das crianças participantes.

\section{Características físicas das salas de aula estudadas}

A sala Infantil 4 (ocupada por crianças entre 4 e 5 anos de idade) e a sala Infantil 5 (ocupada por crianças entre 5 e 6 anos de idade) foram os locais selecionados para este estudo. Ambas as salas localizam-se no nível térreo do Colégio, sendo que a sala Infantil 4 tem a fachada orientada a sudoeste, enquanto a sala Infantil 5 tem orientação nordeste. Na Figura 1 são apresentadas as características arquitetônicas dessas salas de aula.

A orientação das salas caracteriza a iluminação natural e as paisagens que são vistas através das janelas, as quais possuem a mesma altura de peitoril $(1,04 \mathrm{~m})$ e da verga $(2,74 \mathrm{~m})$. Considerando a altura das crianças, na sala Infantil 4 a janela oferece apenas a visualização do céu (Figura 1a), enquanto na sala Infantil 5 é vista uma edificação, vegetação e uma pequena porção do céu (Figura 1b).

Figura 1 - Características das salas de aula e das cenas oferecidas pelas janelas: (a) Infantil 4 e (b) Infantil 5

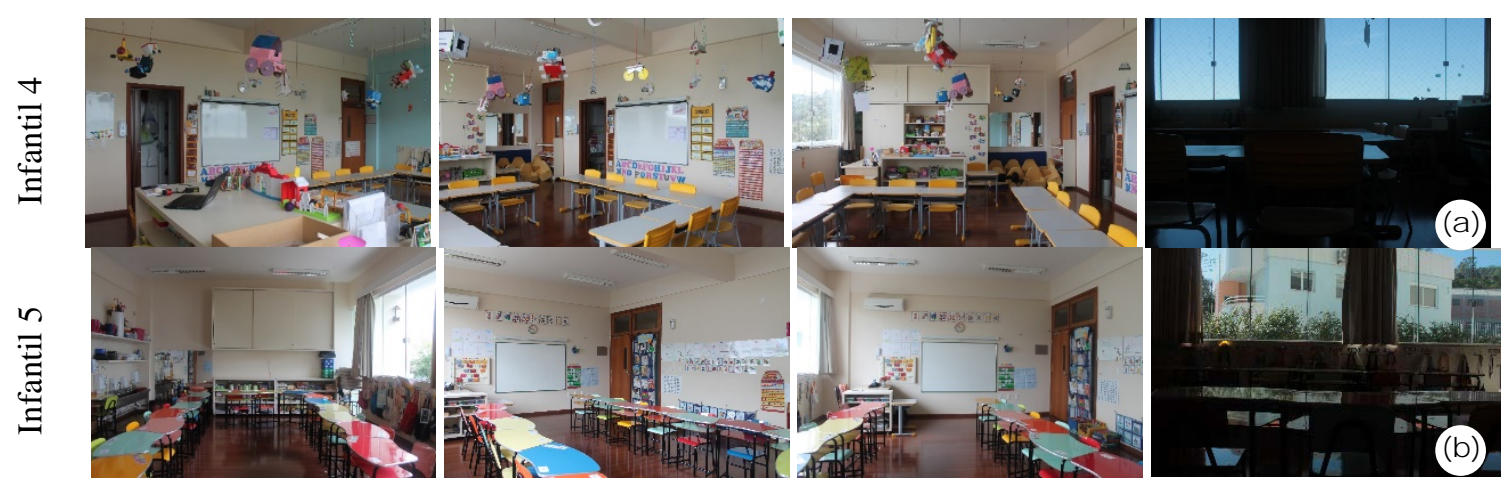


Com relação às características arquitetônicas, ambas as salas possuem planta retangular $(8,10 \mathrm{~m} \mathrm{x}$ $5,50 \mathrm{~m})$ e pé-direito de $3,40 \mathrm{~m}$. No interior, as diferenças entre as duas salas de aula são devidas ao mobiliário, à decoração das paredes e teto, e à cor da tinta de algumas das superfícies, como é o caso de uma parede de cor azul-claro na sala Infantil 4. O sistema de iluminação artificial de ambas as salas é composto de oito luminárias de sobrepor com aletas, cada uma com duas lâmpadas fluorescentes tubulares do tipo T8.

\section{Características de uso gerais das salas: entrevista com as docentes}

O primeiro contato com as características gerais das atividades realizadas nas salas de aula ocorreu mediante uma entrevista semiestruturada com a docente de cada turma. Como método de organização no Colégio, todas as atividades têm um horário programado e duração aproximada de 40 min. A chegada das crianças ocorre entre as $13 \mathrm{~h} \mathrm{e}$ as 13 h30min. Durante esse período as crianças brincam dentro da sala de aula até a turma estar completa, constituindo-se na atividade mais livre realizada em sala.

Em ambas as turmas, a disposição das mesas acontece segundo as atividades realizadas, sendo a docente quem gerencia o tipo de arranjo e localização delas dentro da sala de aula. Os arranjos e agrupamentos variam entre linhas, mesa-redonda e pequenos grupos. A configuração de linhas é utilizada principalmente quando há apresentação de alguma informação no quadro. O principal critério para definir a localização de cada criança está relacionado à disciplina da turma.

Com relação ao mobiliário, as mesas e cadeiras usadas pelas crianças na sala Infantil 4 são todas iguais (cor cinza-claro e amarelo). Na sala Infantil
5 as mesas e cadeiras são de cores variadas e estão identificadas com o nome de cada criança.

\section{Modelos de ocupação das salas: observação e mapeamento comportamental}

Antes de começar a observação comportamental, foi realizada uma visita em cada sala de aula. O intuito dessa visita foi apresentar a pesquisadora às crianças e introduzi-las brevemente nas atividades que seriam desenvolvidas na sala de aula durante as semanas seguintes. Com essa atividade buscou-se familiarizar as crianças com a presença da pesquisadora dentro das salas.

Posteriormente a essa etapa introdutória, foi realizada a observação dos ambientes durante um período. Na sala de aula Infantil 4, a observação foi realizada durante a tarde do dia 12/08, e na sala Infantil 5 durante a tarde do dia 13/08. A observação foi realizada de forma direta e por meio de sequências fotográficas posicionando-se uma câmera em um canto da sala, visando abranger a totalidade do ambiente. Antes de se iniciar cada atividade, houve um período de acomodação e adaptação das crianças. Posteriormente a esse período, foi iniciado o registro fotográfico usando a função time-lapse durante $15 \mathrm{~min}$, tirando-se fotografias a cada $5 \mathrm{~s}$. No total, para cada atividade foram obtidas 180 fotografias. A Tabela 1 apresenta os horários e as atividades realizadas pelas duas turmas durante os dias de observação.

Com base na observação foi realizado o mapeamento comportamental dentro da sala, o que permitiu identificar os modelos de ocupação de cada sala e a localização de cada criança dentro do ambiente.

Tabela 1 - Horário das atividades de cada turma durante o dia da observação e períodos da observação

\begin{tabular}{l|l|l|l|l}
\hline \multirow{2}{*}{ Horário atividades } & \multicolumn{2}{|c|}{ Infantil 4 } & \multicolumn{2}{c}{ Infantil 5 } \\
\cline { 2 - 5 } & \multicolumn{1}{|c}{ Atividade } & \multicolumn{1}{|c}{ Período observado } & \multicolumn{1}{c}{ Atividade } & \multicolumn{1}{c}{ Período observado } \\
\hline 13h a 13h40min & Brinquedo & 13h30min a 13h44min & Brinquedo & 13h30min a 13h44min \\
13h40min a 14h20min & Planejamento & 13h44min a 14h20min & Planejamento & 13h44min a 14h20min \\
14h20min a 15h & Música & Fora da Sala & Parque & Fora da sala \\
15h a 15h45min & Lanche & 15h a 15h45min & Lanche & 15h a 15h45min \\
15h45min a 16h20min & Parque & Fora da sala & Artes & Fora da sala \\
16h20min a 17h05min & Leitura & Fora da Sala & Inglês & 16h30min a 17h10min \\
17h05min a 17h45min & Exposição & 17h15min a 17h45min & Exposição & 17h10min a 17h30min \\
\hline
\end{tabular}




\section{Medição da iluminância (E) durante a observação}

De forma paralela à observação, foram levantados os dados de iluminância (E) em algumas das atividades observadas. No caso da sala Infantil 4 foi possível realizar o levantamento da iluminância a partir das 13h44min (atividade do planejamento). Na sala Infantil 5 o levantamento foi iniciado às 15h30min, durante o lanche das crianças, devido à dinâmica da professora e da turma.

Para os levantamentos das iluminâncias foram utilizados dez sistemas de aquisição remota de dados (data logger) Hobo U-12, da marca Onset. O uso dos sensores do tipo data logger respondeu à necessidade de coletar os dados de iluminância de forma simultânea às atividades de observação e avaliação subjetiva das crianças. O número de pontos para realizar as medições obedeceu à quantidade de sensores data logger disponíveis no LabCon/ARQ-UFSC.

Devido ao fato de esses sensores apresentarem distorção na curva de sensibilidade espectral, foi aplicado um fator de correção com relação aos valores obtidos com o luxímetro T-10, da marca Konica Minolta. Para calcular o fator de correção de cada sensor foram realizadas medições a cada $10 \mathrm{~s}$ em um ambiente iluminado naturalmente e sob quatro níveis de iluminância diferentes: 51,7 lx,
344,8 lx, 681,4 lx e 1.285,0 lx, sendo que esses valores variaram segundo a distância entre o local de medição e a janela. De forma simultânea foram levantados os dados com todos os equipamentos. A Figura 2(a) apresenta as diferenças entre os dados levantados com o luxímetro T-10 e os data logger Hobo U-12.

Devido às variações que todos os sensores apresentaram, não só com relação ao luxímetro T10, senão também entre eles, foi calculada a equação que melhor se ajustasse ao conjunto de dados de cada sensor. A Figura 2(b) apresenta as curvas após a aplicação do fator de correção nos dados levantados com os data logger Hobo U-12.

Como introdução à atividade do dia, já que simultaneamente foram realizados os levantamentos fotométricos, foi feita uma votação sobre a percepção das condições do ambiente luminoso da sala. Foi perguntado para as crianças se achavam a sala "clara” ou "escura”. Essa atividade permitiu introduzir o uso dos equipamentos que estariam dispostos na sala. Depois da familiarização das crianças com os data logger foi solicitado para que não mexessem neles. A disposição dos sensores para os levantamentos da iluminância dentro da sala durante as atividades esteve sujeita aos arranjos do mobiliário definidos pelas docentes, diferenciando-se o tamanho das áreas levantadas em cada sala.

Figura 2 - Variações na E: luxímetro T-10 versus Data logger Hobo U-12 (a) antes e (b) depois de aplicar o fator de correção
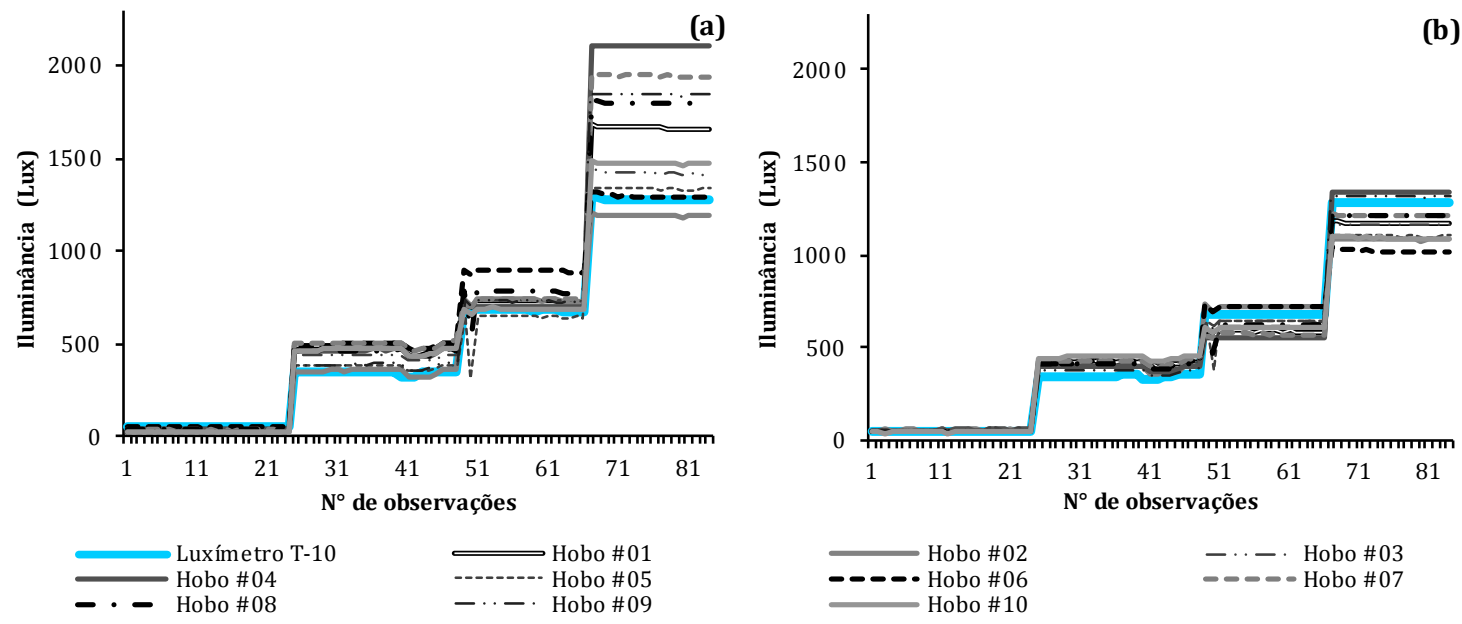


\section{Avaliação da preferência do ambiente luminoso e tipo de céu}

A preferência pelo ambiente luminoso da sala foi levantada por meio de uma entrevista individual durante os dias 25/08 (Infantil 4) e 26/08 (Infantil 5). Depois de uma breve introdução à atividade, e reforçando a importância da participação de cada criança nessa fase da pesquisa, foi apresentada uma sequência de perguntas, a qual estruturou a entrevista. As opções de resposta foram apresentadas por meio de fotografias da própria sala de aula de cada criança. As fotografias foram disponibilizadas imediatamente após a formulação das seguintes perguntas:

(a) Você prefere a sala de aula quando as cortinas estão abertas ou fechadas? Saberia me dizer por que gosta dela assim?

(b) E quando as cortinas da sala estão fechadas, você prefere que as lâmpadas estejam ligadas ou desligadas? Saberia me dizer por que gosta mais quando as lâmpadas estão ligadas/desligadas?

(c) E quando as cortinas estão abertas, você olha pela janela da sala de aula? e

(d) E quando você olha pela janela da sala de aula, qual destes céus você gosta mais de ver:

- um céu azul sem nuvens?;

- um céu azul com poucas nuvens?;

- um céu com muitas nuvens?; ou

- um céu com muitas nuvens e cinza?

A preferência por determinada condição do céu foi identificada através de fotografias da paisagem vista através da janela de cada sala de aula. Em cada imagem foram variadas as porções de céu visível
(Figura 3), resultando em quatro imagens para cada sala de aula. No caso da sala Infantil 4, considerando a altura dos observadores, a visual da janela é ocupada completamente pelo céu. Na sala Infantil 5 apenas pequenas porções de céu aparecem, localizadas nos dois cantos superiores da janela.

Devido à programação curricular de cada turma, foi necessário realizar as entrevistas em uma sala diferente das salas de aula estudadas.

\section{Avaliação da preferência pela paisagem vista através da janela}

O levantamento da preferência pelo tipo de paisagem visto através da janela da sala de aula foi obtido por meio de desenhos. A pergunta "O que você mais gosta de ver quando olha pela janela da sala?” referiu-se à preferência de cada criança pelas características das paisagens vistas através da janela. Com uma fotografia da sala de aula, com a área da janela em branco, foi solicitado a cada criança desenhar os elementos da paisagem que, vistos pela janela da sala de aula, fossem seus preferidos.

A análise dos desenhos foi realizada de forma descritiva, agrupando os elementos desenhados em quatro categorias: paisagem natural, paisagem construída, outros e não relacionados. À categoria “outros” pertencem os elementos que, mesmo possíveis de ser vistos através da janela da sala, não pertenceram às categorias "paisagem natural” ou "paisagem construída”. Na categoria "não relacionados” foram agrupados os elementos que não fazem parte das paisagens vistas através das janelas das salas de aula, tais como quadra de basquete, videogame, a família, barraca e lagoa.

Figura 3 - Imagens das janelas usadas nas montagens para avaliação do céu preferido: a) Infantil 4 e b) Infantil 5

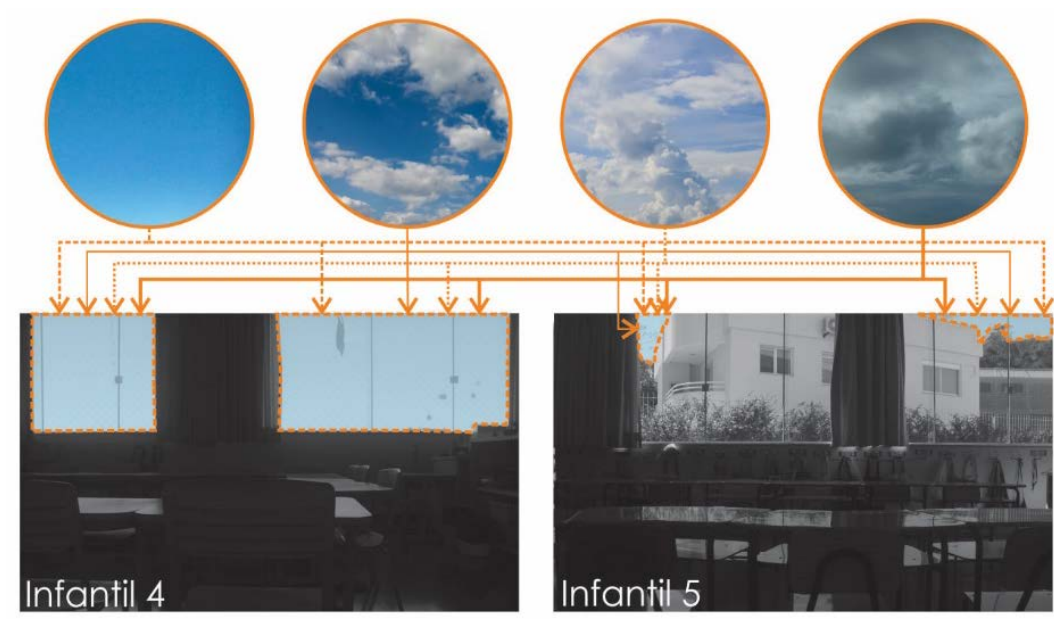




\section{Resultados}

\section{Modelos de uso e ocupação da sala}

Durante o período de observação estiveram presentes 13 crianças na sala Infantil 4 e 17 crianças na sala Infantil 5. Do total de crianças presentes nas salas $(n=30) 16$ eram meninas e 14 eram meninos. Com relação à idade, 9 crianças estavam com 4 anos, 18 crianças estavam com 5 anos e 3 crianças estavam com 6 anos de idade.

A Figura 4(a) apresenta a comparação da área total das salas de aula com a área ocupada pelo mobiliário (Infantil 4, área igual a 13,63 $\mathrm{m}^{2}$ e Infantil 5, área igual a 12,17 $\mathrm{m}^{2}$ ), a área útil do ambiente (Infantil 4, área igual a 30,87 $\mathrm{m}^{2}$ e Infantil 5 , área igual a 32,33 $\mathrm{m}^{2}$ ) e a somatória das áreas usadas durante as atividades. Ao sobrepor as áreas ocupadas durante todas as atividades, a área usada pelas crianças foi igual a 53,69 $\mathrm{m}^{2}$ na sala Infantil 4 e igual a $61,00 \mathrm{~m}^{2}$ na sala Infantil 5 . Com relação ao tempo de uso das salas, as atividades realizadas durante o período de observação representaram $46 \%$ e $65 \%$ do tempo total nas salas Infantil 4 e 5 respectivamente (Figura 4(b)).

Ao comparar a área ocupada na atividade "Brinquedo" e na atividade "Lanche” é possível identificar que, mesmo sendo a primeira atividade mais livre, a área que ocuparam as crianças dentro da sala foi menor. Contudo, ao observar o mapeamento comportamental (Figura 5), é possível identificar como durante a atividade "Brinquedo" as crianças estiveram em pequenos agrupamentos em diferentes áreas das salas. No caso do "Planejamento", embora as áreas ocupadas em ambas as turmas fossem similares às áreas ocupadas durante a atividade "Brinquedo", o tempo gasto na primeira atividade foi maior.

Na Figura 5 é apresentada a localização e as posturas das crianças durante cada atividade (meninas em lilás e meninos em verde). As áreas ocupadas durante o período de observação de cada atividade também são apresentadas nas plantas. No caso da atividade "Brinquedo", em ambas as turmas foram identificados 3 a 4 agrupamentos de crianças. No "Planejamento" as crianças estiveram posicionadas de costas para as janelas das salas, olhando em direção ao quadro. Durante o "Lanche" e a "Aula de Inglês" cada criança esteve ocupando sua carteira, conforme a disposição sugerida pelas docentes. Na última atividade do dia "Exposição" as crianças estiveram agrupadas e sentadas em cadeiras ou no piso. A posição das cortinas e o uso da iluminação artificial foram indicados para cada período observado.

A Figura 6 apresenta a somatória das áreas usadas dentro de cada sala de aula. É possível identificar a influência da disposição do mobiliário na ocupação do ambiente. Independentemente da atividade, as crianças adaptaram-se e usaram as áreas livres da sala para realizar as atividades. Igualmente é possível identificar como as crianças, quando têm liberdade para selecionar em qual lugar da sala querem permanecer, preferiram estar mais próximas do centro do ambiente.

\section{Aproximação à percepção visual e características do ambiente Iuminoso}

À chegada das crianças nas salas as lâmpadas estavam desligadas e as cortinas abertas.

Figura 4 - (a) Áreas e usos dentro das salas e (b) tempo de uso versus área ocupada durante as atividades
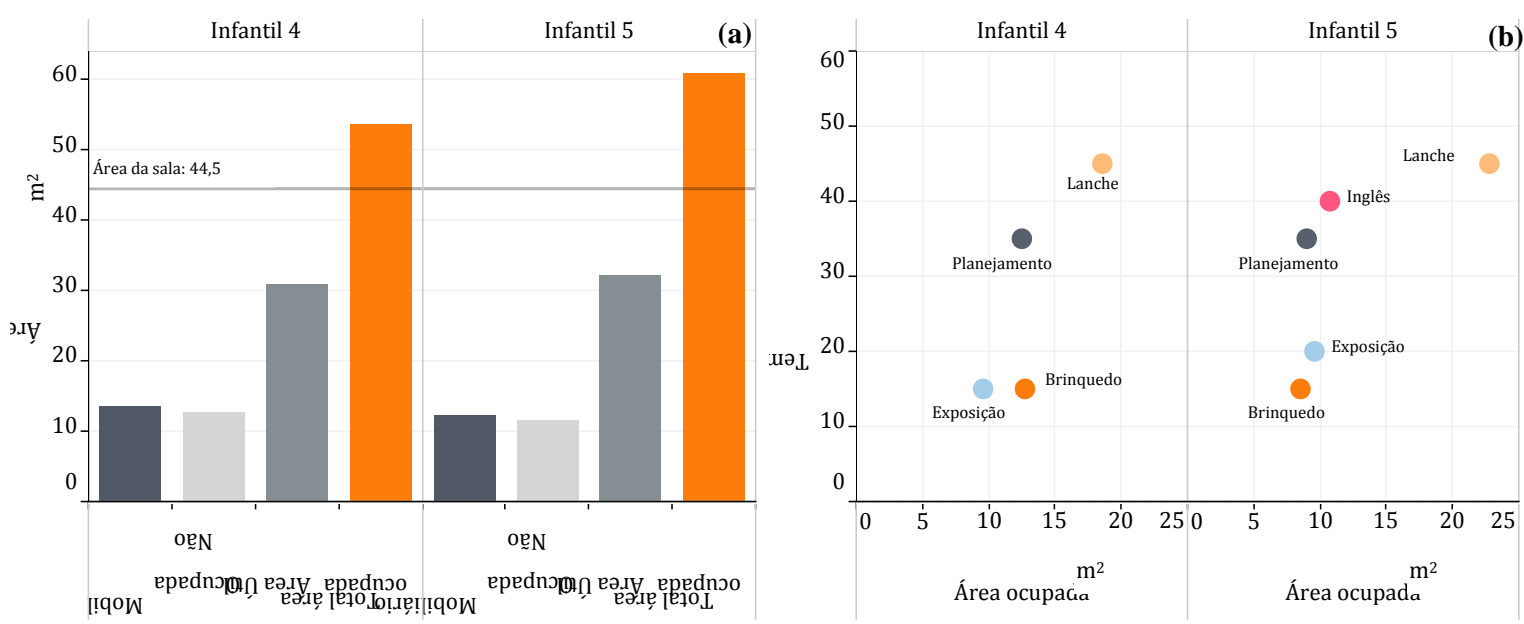
Figura 5 - Mapeamento comportamental das atividades observadas nos dias 12/08/2015 (Infantil 4) e 13/08/2015 (Infantil 5)

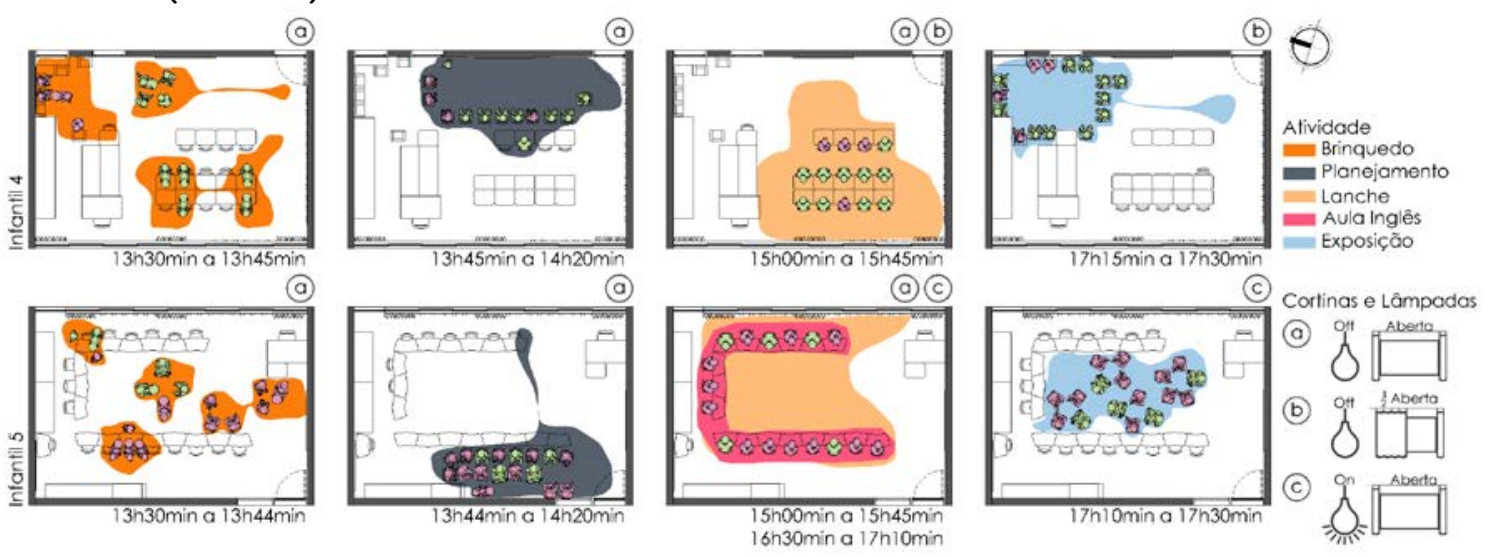

Figura 6 - Sobreposição das áreas ocupadas em cada sala de aula

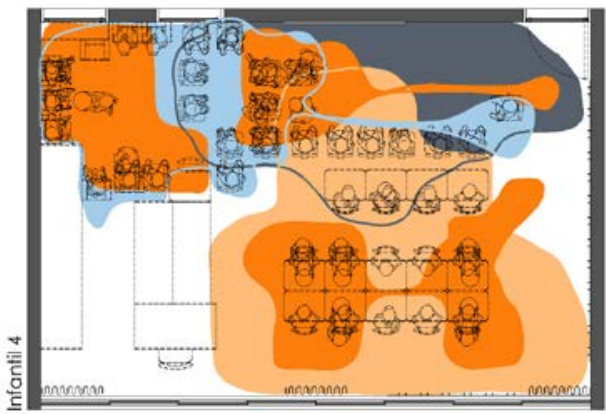

Na Figura 7 são apresentados os horários das votações realizadas em cada sala, número de crianças presentes e resultado obtido nesse processo. Na sala Infantil 4 a votação foi realizada antes do início das atividades do dia (às 13h), e das 11 crianças presentes só 1 criança percebeu a sala como "escura". Foi realizada mais uma votação para decidir se as lâmpadas deveriam permanecer desligadas ou se deveriam ser ligadas. Dez crianças acharam a sala "clara", motivo pelo qual as lâmpadas permaneceram desligadas. Com relação à operação das cortinas, durante a hora do lanche (15h30min), 5 crianças pediram para fechar metade das cortinas devido à radiação solar incidente sobre elas. Sob essa condição, as lâmpadas permaneceram desligadas. Ao finalizar as atividades (17h30min) foi realizada novamente a votação da percepção, e das 13 crianças presentes nesse momento 10 gostaram da sala "escurinha”, enquanto 3 preferiam que as lâmpadas fossem ligadas. Na sala Infantil 5, durante o lanche (15h30min), as 17 crianças acharam a sala de aula "escura" e preferiam ter as lâmpadas ligadas naquele momento. Ao finalizar o dia (17h), foi realizada mais uma votação sobre a percepção da iluminação da sala de aula. Embora as crianças tenham percebido a sala de aula "escura" e a achado agradável, a maioria das crianças preferiu ligar as lâmpadas.

Na Figura 8(a) são apresentadas as condições de uso das lâmpadas durante as atividades realizadas em cada sala, a área da sala com $\mathrm{E} \geq 500$ lx e $\mathrm{E}<500$ lx, assim como o cálculo de uniformidade da iluminação durante as atividades.

Na sala Infantil 4, na qual não houve operação da iluminação artificial, as áreas com $\mathrm{E} \geq 500 \mathrm{~lx}$ foram maiores do que as áreas com $\mathrm{E}<500$ lx: entre 18,5 $\mathrm{m}^{2}$ e $31,5 \mathrm{~m}^{2}$ no primeiro caso, e entre $13 \mathrm{~m}^{2}$ e 26 $\mathrm{m}^{2}$ no segundo caso (Figura 8(a)). A localização das crianças com relação ao parâmetro analisado foi variável, porém, na maioria das atividades, a maior parte da turma esteve localizada em áreas com $\mathrm{E} \geq$ 500 lx (Figura 9). Na sala Infantil 5, e durante as atividades nas quais as lâmpadas estiveram ligadas, a iluminância do ambiente foi maior ou igual a 500 lx. Durante o planejamento, atividade na qual as lâmpadas estiveram desligadas, a maior parte da área da sala esteve com menos de 500 lx (Figura 8(a)). Nessa atividade as crianças estiveram localizadas na área menos iluminada da sala (Figura 9), porém com E média de 467 lx.

No caso da iluminação artificial, a uniformidade, razão entre o valor mínimo e o valor médio da 
iluminância, deve ser superior a 0,5 e próxima a 1 (ABNT, 2013). Na Figura 8(a) é possível identificar que, nas atividades realizadas durante o uso das lâmpadas no Infantil 5, o valor de uniformidade esteve dentro da faixa recomendada pela norma. $\mathrm{Na}$ sala Infantil 4, onde todas as atividades foram realizadas sob iluminação natural, os valores de uniformidade foram inferiores a 0,5.

Figura 7 - Esquema dos resultados das votações realizadas nas salas de aula

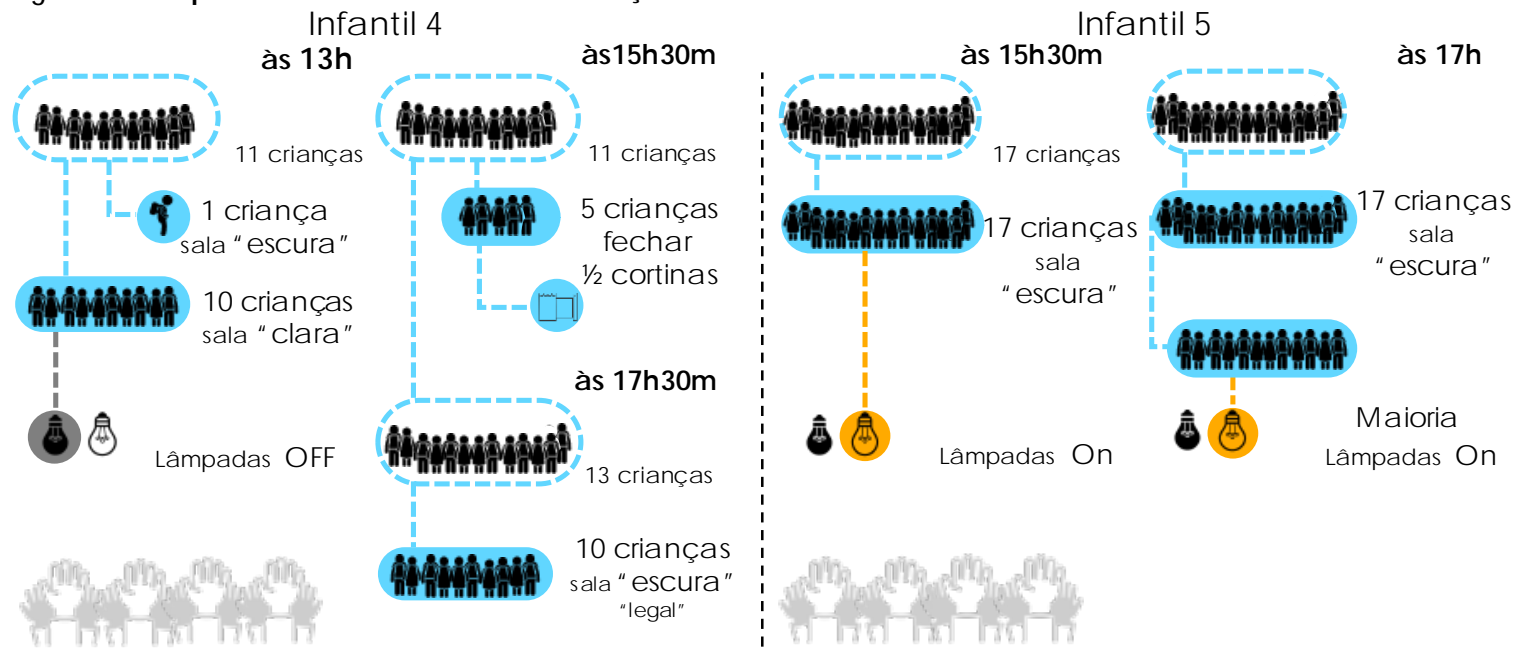

Figura 8 - (a) Área por atividade em função da curva de 500 Ix e uniformidade da iluminação, (c) tempo versus $\mathrm{E}_{\text {média }}$ da atividade

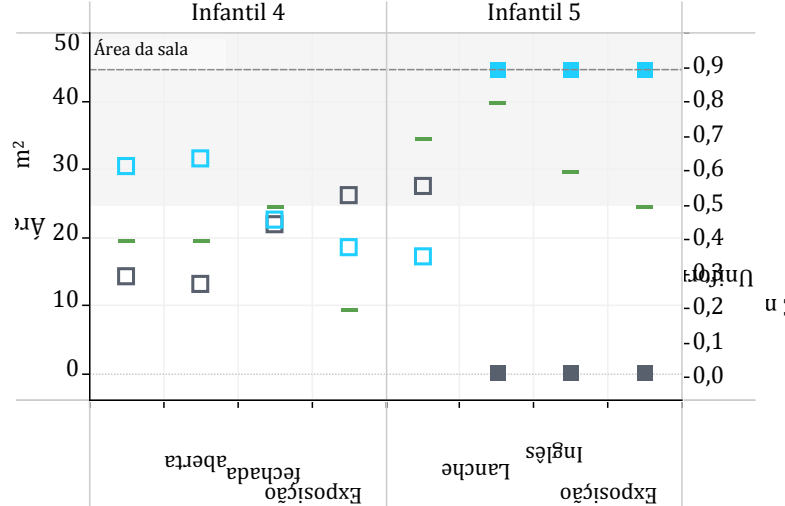

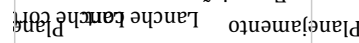

Área com E $\geq 500$ Lux —Área com E < 500 Lux —Uniformidade

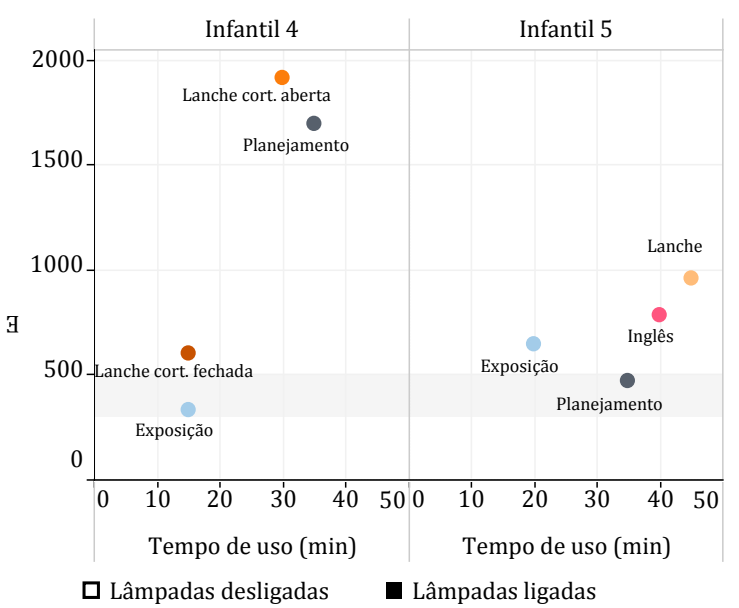

口 Lâmpadas desligadas

Figura 9 - Distribuição da iluminância no ambiente em função da curva de 500 lx
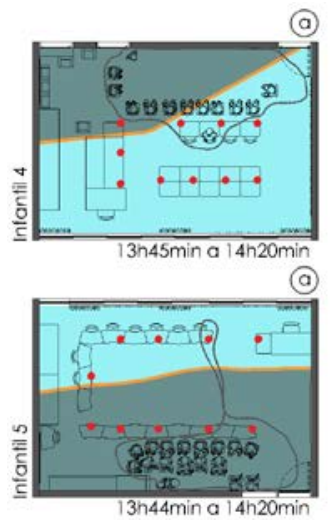

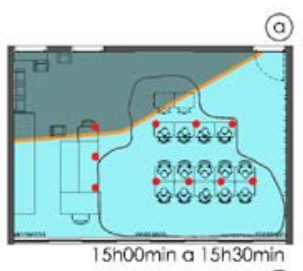

(C)

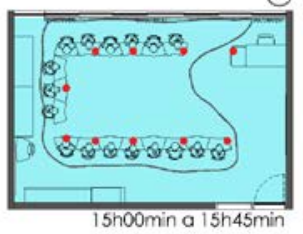

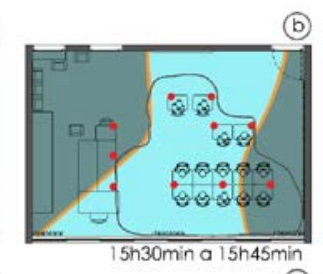

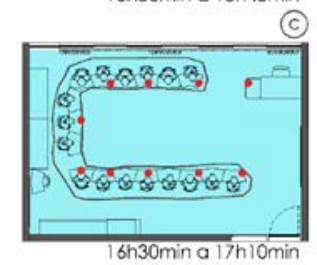

(b)

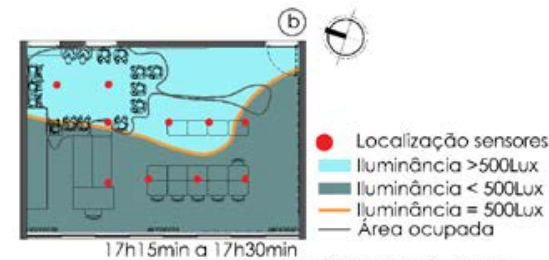

(c)

Cortinas e Lâmpadas

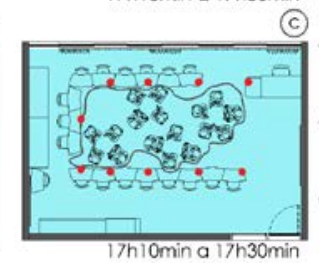

(b)

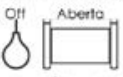

3

$\int_{1}^{\infty}$ 
De acordo com a norma NBR ISO/CIE 8995-1 (ABNT, 2013), a iluminância média a ser mantida em salas de aula deve estar entre $300 \mathrm{~lx}$ e $500 \mathrm{~lx}$, segundo a atividade que seja realizada no ambiente. No caso da sala Infantil 4 a menor $E_{\text {média }}(334$ lx) foi durante a atividade "Exposição”, a qual foi realizada ao finalizar o dia, durante $15 \mathrm{~min}$, e com a metade das cortinas fechadas (Figura 8(b)). No caso da sala Infantil 5, a única atividade realizada sem uso da iluminação artificial foi "Planejamento" $\left(E_{\text {média }}=467 \mathrm{~lx}\right)$, a qual teve duração de $35 \mathrm{~min}$ (Figura 8(b)). Embora a $E_{\text {média }}$ tenha se apresentado dentro da faixa dos valores recomendados pela norma, as crianças e a docente preferiram o ambiente com as lâmpadas ligadas ( $\mathrm{E}_{\text {média }}=955 \mathrm{~lx}$ durante o "Lanche").

\section{Você prefere a sala com as cortinas abertas ou fechadas?}

No dia da entrevista estavam presentes 11 crianças na sala Infantil 4 e 16 na sala Infantil 5. Das 27 crianças 17 eram meninas e 10 eram meninos. Com relação à idade, 8 crianças estavam com 4 anos, 17 crianças estavam com 5 anos, e 2 crianças com 6 anos.

As respostas às duas primeiras perguntas:

(a) Você prefere a sala de aula quando as cortinas estão abertas ou fechadas? e

(b) Quando as cortinas estão fechadas, você prefere que as lâmpadas estejam ligadas ou desligadas?

São apresentadas na Figura 10(a). Os dados dos votos são apresentados por idade, e o valor total de votos, para cada cenário.
No total, a opção com a cortina aberta recebeu 19 votos, e a opção com a cortina fechada, 12 votos (Figura 10(a)). O total de votos obtidos (31) foi maior que o número de crianças que participaram da entrevista por quatro crianças terem expressado a preferência no uso da cortina e das lâmpadas pelo tipo de atividade ou incidência de sol. Com relação ao uso da iluminação artificial, quando as cortinas estão fechadas, a opção com as lâmpadas ligadas teve o total de 21 votos, e a opção com lâmpadas desligadas teve o total de 8 votos. A Figura 10(b) apresenta os votos de preferência no uso das lâmpadas quando as cortinas estiveram fechadas. Das 12 crianças que preferiram as cortinas fechadas, a configuração "Cortina fechada/Lâmpadas ligadas” teve 8 votos enquanto a configuração "Cortina fechada/Lâmpadas desligadas” teve 5 votos de preferência. De forma geral, os dados levantados permitem identificar a preferência das crianças quando o ambiente luminoso da sala de aula é mais claro (cortinas abertas e lâmpadas ligadas).

Na Figura 11 são apresentados os motivos para a preferência da posição das cortinas e uso da iluminação artificial. Foi possível identificar que as crianças, principalmente as mais velhas, associaram as características da iluminação da sala com tarefas visuais ou atividades.

Segundo as respostas obtidas, foi identificado um aspecto da avaliação subjetiva do ambiente luminoso com o qual cada um dos motivos da preferência foi relacionado. Esses aspectos foram visibilidade do exterior, tarefa visual, percepção visual e conforto visual.

\section{Figura 10 - Votos obtidos nas perguntas de preferência com relação à posição das cortinas e uso das} lâmpadas

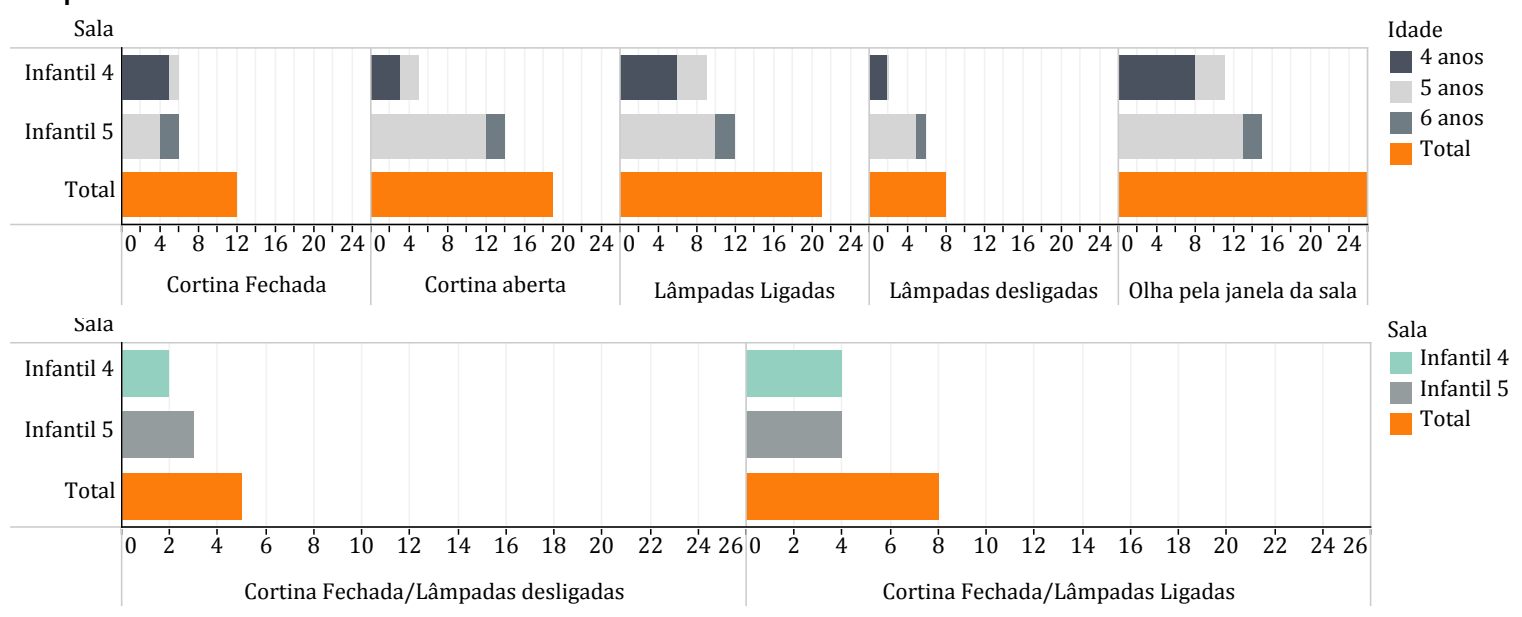


Figura 11 - (a) Motivos de preferência no uso das cortinas e (b) lâmpadas quando as cortinas estão fechadas

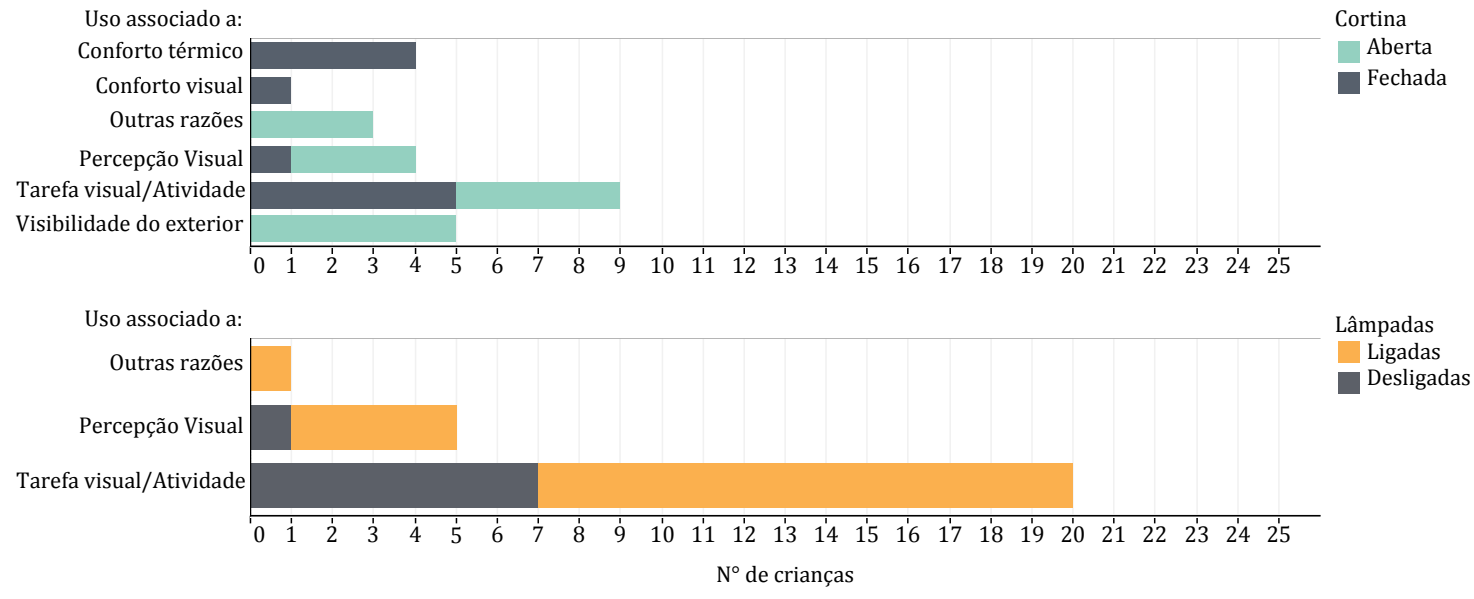

As respostas das crianças permitiram identificar a relação que elas fazem entre as condições de iluminação no interior da sala e as características da atividade a ser realizada. Outro aspecto identificado, nas quatro opções de resposta, foi aquele que remete à percepção do ambiente visual. No entanto, o principal motivo para preferir as cortinas abertas é a possibilidade de olhar para o exterior, enquanto o segundo motivo para preferir as cortinas fechadas está relacionado com o conforto térmico.

\section{Qual tipo de céu você prefere ver pela janela da sala?}

O número de votos para o tipo de céu preferido por cada uma das crianças é apresentado no Figura 12(a). Os resultados revelaram que o céu limpo (céu azul sem nuvens) foi o mais preferido pelas crianças (21 votos), seguido pelo céu com poucas e muitas nuvens (3 votos para cada um).

Os motivos de preferência manifestados pelas crianças no momento de escolher um dos tipos de céu estiveram associados a atividades que poderiam ser realizadas no exterior (brincar), características do céu (dia bonito, dia claro, tem sol), percepção visual (a sala fica clara, enxerga melhor) e outras razões (fica feliz, gosta da cor azul). Os principais motivos manifestados pelas crianças para preferirem o céu limpo estiveram relacionados com a possibilidade de realizar atividades ao ar livre (10 votos), tanto como a percepção de que o dia fica mais bonito (14 votos) (Figura 12(b)). As duas condições do céu com nuvens foram selecionadas pelas crianças ( 2 votos para cada) como resultado da preferência pelas nuvens e a aparência do céu (fica mais bonito). Apenas uma criança preferiu o céu cinza.

\section{Preferência pelos elementos da paisagem vista através da janela}

A atividade de desenho da paisagem vista através da janela foi realizada nos dias 19/08/2015 (Infantil 4) e 20/08/2015 (Infantil 5). Para obter as informações de preferência de forma individual, uma imagem da sala de aula com o espaço da janela em branco foi fornecida a cada criança.

No dia da atividade na sala Infantil 4 o arranjo das mesas dividiu o espaço em dois ambientes. Nesse dia estavam presentes 13 crianças na sala de aula: 9 meninos e 4 meninas. Nessa sala o desenho foi realizado em pequenos grupos (de 3 a 6 crianças), localizados em um dos ambientes. Ao finalizar o desenho, os grupos passaram ao outro ambiente para realizar outra atividade com a professora da turma. Previamente foi perguntado para as crianças se reconheciam a imagem sobre a qual seria realizado o desenho. Iniciada a atividade, foi solicitado às crianças desenhar aqueles elementos que, vistos através da janela da sala de aula, eram seus preferidos. Nesta sala, na altura do observador, o céu era o único elemento visível da paisagem, motivo pelo qual as crianças pediram para ficar de pé sobre as cadeiras e assim conseguir ver a paisagem através da janela. Adicionalmente foi solicitado às crianças não comentar sobre seu desenho enquanto era realizado, já que ao final da atividade elas o apresentariam para os colegas. Por meio da socialização dos desenhos foram identificados os elementos desenhados por cada criança. Em média, o tempo que cada subgrupo do Infantil 4 demorou para realizar o desenho foi de aproximadamente17 min, para uma duração total da atividade de aproximadamente $53 \mathrm{~min}$.

Na sala Infantil 5 estavam presentes 16 crianças no momento da atividade: 11 meninas e 5 meninos. 
Nessa sala, o desenho também foi realizado em pequenos grupos (de 4 e 5 crianças) de forma simultânea. Previamente à conformação dos grupos, foi realizada a apresentação e a explicação da atividade para a turma inteira. As crianças dessa turma também identificaram sua sala de aula na fotografia apresentada. O tempo utilizado para realizar essa atividade na sala Infantil 5 foi de $\simeq 34$ min. A Figura 13 mostra alguns dos desenhos realizados por crianças das duas salas de aula.

\section{Figura 12 - (a) Votos de preferência pelo tipo de céu e (b) motivos da preferência}

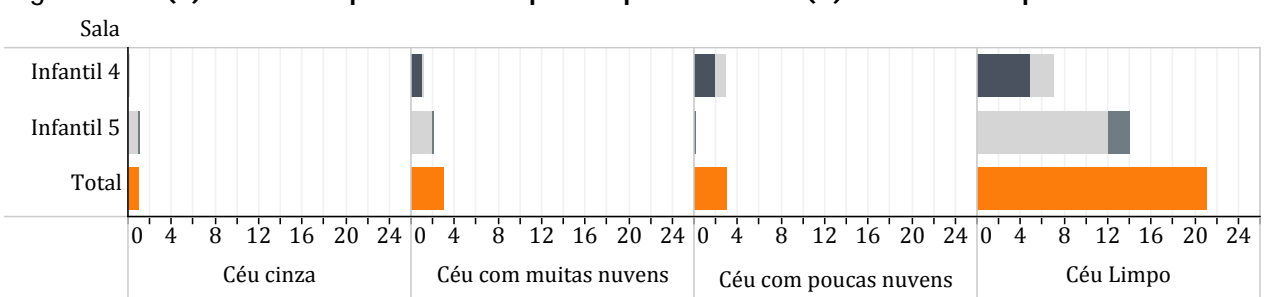

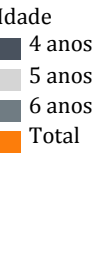

Tipo de céu Cinza

Com muitas nuvens

Com poucas nuvens Limpo

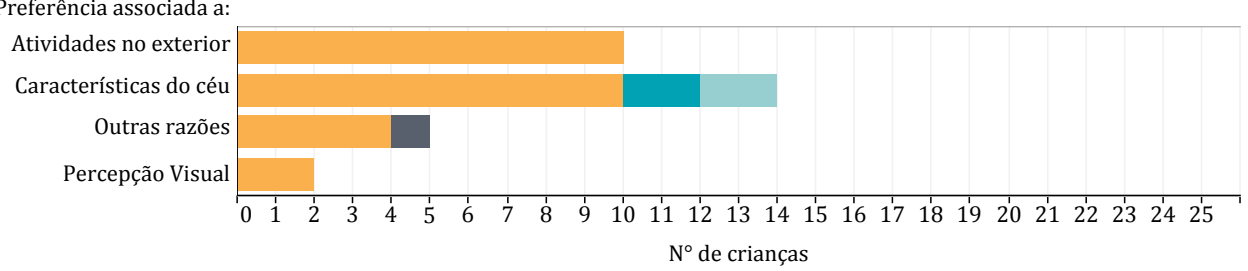

Figura 13 - Desenhos realizados por algumas das crianças de cada turma e sua descrição
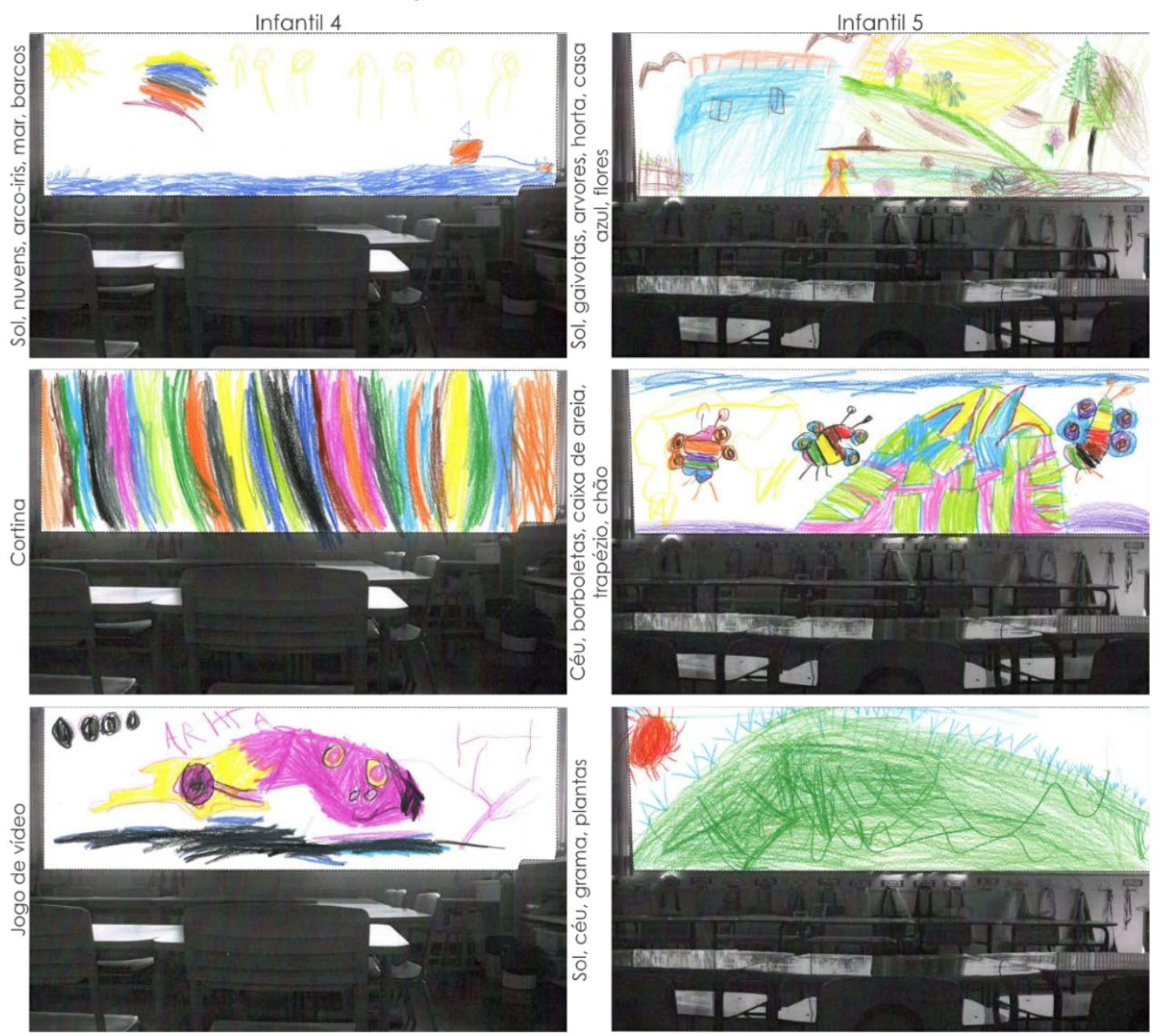
Nos desenhos realizados pelas crianças da sala Infantil 4 foram identificados 22 elementos diferentes, enquanto nos desenhos das crianças da sala Infantil 5 foram encontrados 24 elementos. $\mathrm{Na}$ Tabela 2 são apresentados os dados quantitativos dos desenhos. Neste estudo, o total de elementos desenhados representa a somatória dos diferentes elementos identificados, sem considerar sua repetição no próprio desenho (ex.: número de nuvens, número de árvores, etc.).

A Figura 14 apresenta os elementos identificados nos 29 desenhos realizados pelas crianças das duas salas de aula. Em verde aparecem os elementos presentes nos desenhos das crianças da sala Infantil 4 , e em cinza, os elementos presentes nos desenhos das crianças da sala Infantil 5.

Nos 29 desenhos os elementos com maior frequência de ocorrência foram o sol, as árvores e o céu (presentes em 19, 12 e 10 desenhos respectivamente). O sol, o arco-íris e as nuvens foram elementos recorrentes nos desenhos das crianças da sala Infantil 4 (em seis, quatro e três desenhos respectivamente). Na sala Infantil 5 os elementos recorrentes foram o sol (13), as árvores (11) e as flores (9).

Na Tabela 3 é apresentada a classificação dos elementos dos desenhos nas categorias paisagem natural, paisagem construída, outros e não relacionados. Alguns elementos das categorias paisagem natural e paisagem construída foram comuns em alguns dos desenhos de ambas as salas de aula (ex.: árvore, céu, chuva, grama, mar, morro, nuvens, pássaros, rio, sol, casa), já que podiam ser vistos através de ambas as janelas. As diferenças encontradas nos elementos das categorias evidenciam as diferenças visuais oferecidas pelas janelas.

As Figuras 15(a) e 15(b) apresentam a distribuição das quatro categorias de análise dos elementos por sala de aula.

Tabela 2 - Estatística dos desenhos

\begin{tabular}{l|c|c|c}
\hline \multicolumn{1}{c|}{ Medida } & Infantil 4 & Infantil 5 & Total \\
\hline Número de desenhos & 13 & 16 & 29 \\
Número de elementos identificados & 22 & 24 & 66 \\
Total de elementos desenhados & 39 & 98 & 137 \\
Média de elementos por desenho & 1,77 & 4,08 & 3,60 \\
Desvio padrão de elementos por desenho & 1,2 & 3,68 & 3,96 \\
\hline
\end{tabular}

Figura 14 - Elementos presentes nos desenhos

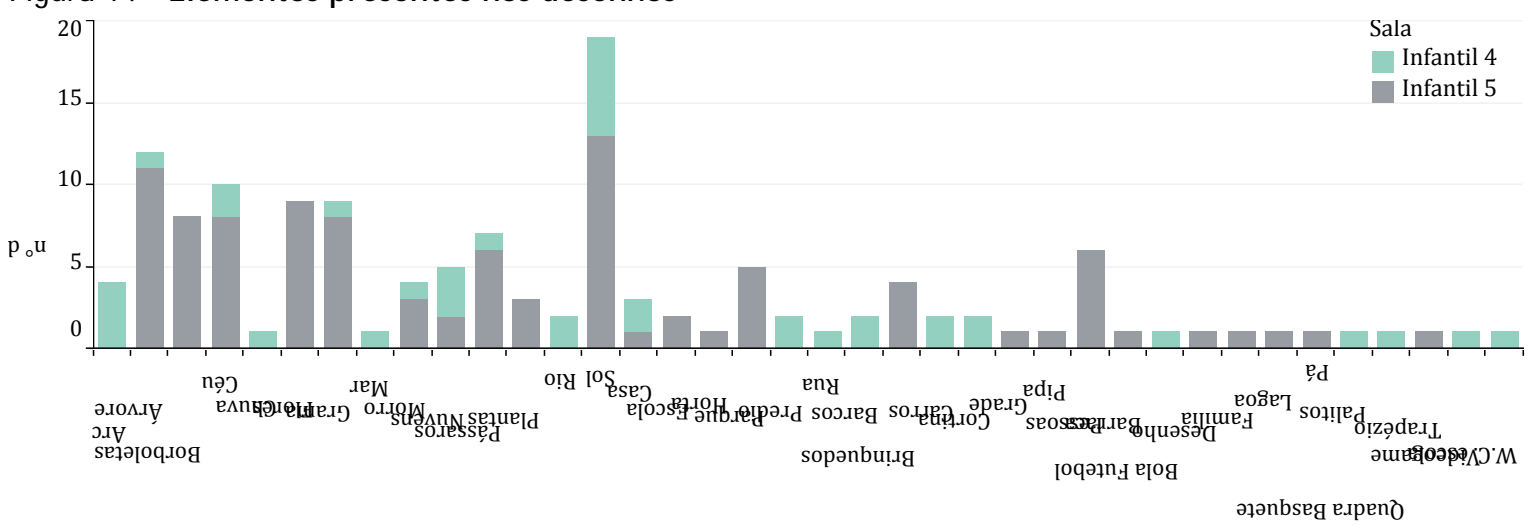

Tabela 3 - Elementos dos desenhos nas categorias de análise

\begin{tabular}{l|l|l}
\hline \multicolumn{1}{c|}{ Categoria } & \multicolumn{1}{c}{ Infantil 4 } & \multicolumn{1}{c}{ Infantil 5 } \\
\hline Paisagem natural & $\begin{array}{l}\text { Arco-íris, árvore, céu, chuva, grama, } \\
\text { mar, morro, nuvens, pássaros, rio, sol }\end{array}$ & $\begin{array}{l}\text { Árvore, borboletas, céu, flores, grama, } \\
\text { morro, nuvens, pássaros, plantas, sol }\end{array}$ \\
\hline Paisagem construída & Casa, prédio, rua & Casa, escola, horta, parque \\
\hline Outros & Barcos, carro, cortina & Brinquedos, grade, pipa, pessoas \\
\hline Não relacionados & $\begin{array}{l}\text { Bola futebol, quadra basquete, } \\
\text { palitos, videogame, WC escola }\end{array}$ & $\begin{array}{l}\text { Barraca, desenho, família, lagoa, pá, } \\
\text { trapézio }\end{array}$ \\
\hline
\end{tabular}


Figura 15 - Categorias dos elementos encontrados nos desenhos (a) Infantil 4, (b) Infantil 5 e (c) total

(a)

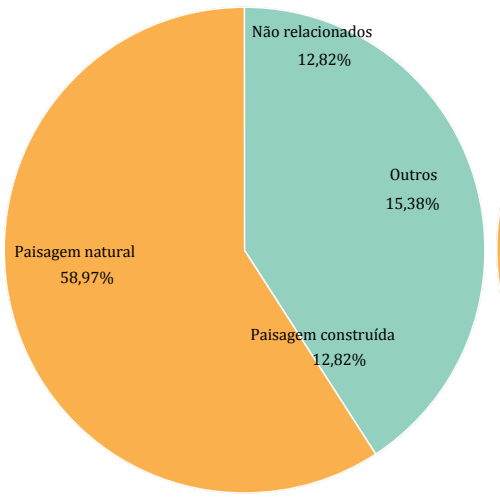

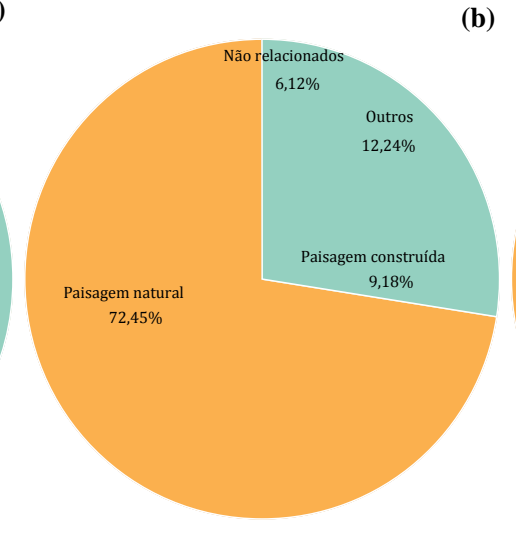

(b)

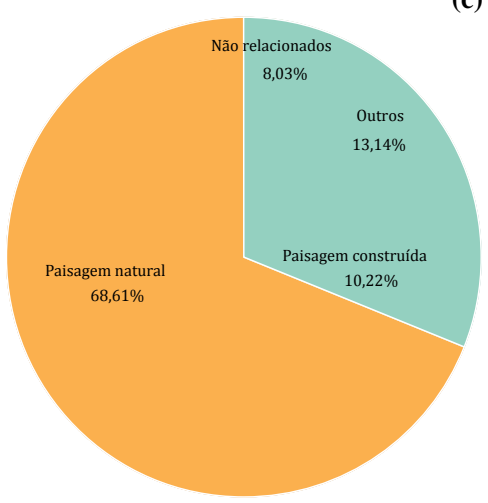

Nos desenhos de ambas as turmas, a categoria de maior peso foi "Paisagem natural", com aproximadamente 59\% e aproximadamente $72 \%$ na sala Infantil 4 e Infantil 5 respectivamente. A categoria "Outros" foi a segunda com mais elementos, aproximadamente $15 \%$ e aproximadamente $12 \%$ do total, sendo a segunda em peso. Nos desenhos de Infantil 4, ambas as categorias "Paisagem construída" e "Não relacionados" tiveram o mesmo número de elementos, aproximadamente $13 \%$. Nos desenhos de Infantil 5 a categoria "Paisagem construída" teve aproximadamente $9 \%$ dos elementos desenhados, e a categoria "Não relacionados" teve aproximadamente 6\%. A Figura 15(c) apresenta o peso de cada categoria para o total dos desenhos.

Sendo os elementos da categoria "Paisagem natural" os de maior peso nos desenhos de ambas as salas (aproximadamente 68\%), uma análise dessa categoria foi realizada. Foi possível identificar cinco subcategorias na "Paisagem natural": elementos presentes na abóbada celeste, vegetação, animais, elementos com água e elementos topográficos (Figura 16).

Os elementos desenhados na subcategoria “Abóbada” (sol, céu, nuvens, arco-íris), totalizaram aproximadamente $40 \%$ dos elementos da "Paisagem natural", sendo o elemento "sol" o de maior peso na categoria (aproximadamente 20\%) e, por sua vez, na subcategoria (aproximadamente $50 \%$ ). A vegetação teve aproximadamente $35 \%$ dos elementos dessa categoria, sendo a segunda subcategoria de maior peso dentro dos elementos da "Paisagem natural”. Conforme as análises prévias, pode-se afirmar que existe preferência das crianças por ver elementos da natureza na paisagem, principalmente elementos da abóbada celeste e da vegetação.

No entanto, elementos da natureza não foram encontrados em todos os desenhos. A Figura 17 apresenta a percentagem de elementos, por categoria, no desenho realizado por cada participante. Nos desenhos realizados pelas crianças da sala Infantil 5, 100\% dos participantes incluíram algum elemento da natureza: aproximadamente $12,5 \%$ dos desenhos estiveram constituídos em $50 \%$ por elementos da natureza. $\mathrm{Na}$ sala Infantil 4, apenas $46 \%$ dos participantes incluíram algum elemento da natureza no desenho, sendo aproximadamente $23 \%$ dos desenhos constituídos em sua totalidade por elementos da paisagem natural.

\section{Preferência por um tipo de paisagem}

A partir da análise prévia foi realizada uma tentativa de aproximação à preferência de cada criança pelo tipo de paisagem. Com base na proporção dos elementos pertencentes a cada categoria de análise foi identificada a tendência que existiria por uma paisagem determinada. Para isso, foram estabelecidas as seguintes regras:

(a) se a quantidade de elementos desenhados na categoria "Paisagem natural” for maior ou igual que $50 \%$ e a quantidade de elementos desenhados na categoria "Paisagem construída" for menor que $50 \%$, a paisagem desenhada se enquadra na classificação de "Predominantemente natural";

(b) se a quantidade de elementos desenhados na categoria "Paisagem construída" for maior ou igual a $50 \%$, a paisagem desenhada se enquadra na classificação "Predominantemente construída"; e

(c) se os elementos desenhados pertencem às categorias “Outros” ou "Não relacionados”, a preferência pelo tipo de paisagem não pode ser estabelecida, e a paisagem do desenho fica "Sem categoria”.

Em ambas as salas, e de acordo com as regras estabelecidas, as paisagens "Predominantemente naturais” foram as preferidas pelas crianças (Figura 
18): aproximadamente $20 \%$ dos desenhos de Infantil 4 e $100 \%$ dos desenhos de Infantil 5. Na sala Infantil 4, aproximadamente $17 \%$ dos desenhos tiveram unicamente elementos nas categorias
“Outros” e "Não relacionados”, o que impediu a classificação desses desenhos em algum dos dois tipos de paisagem ("Sem categoria”).

\section{Figura 16- Peso dos elementos dentro da categoria Paisagem Natural e de cada subcategoria}

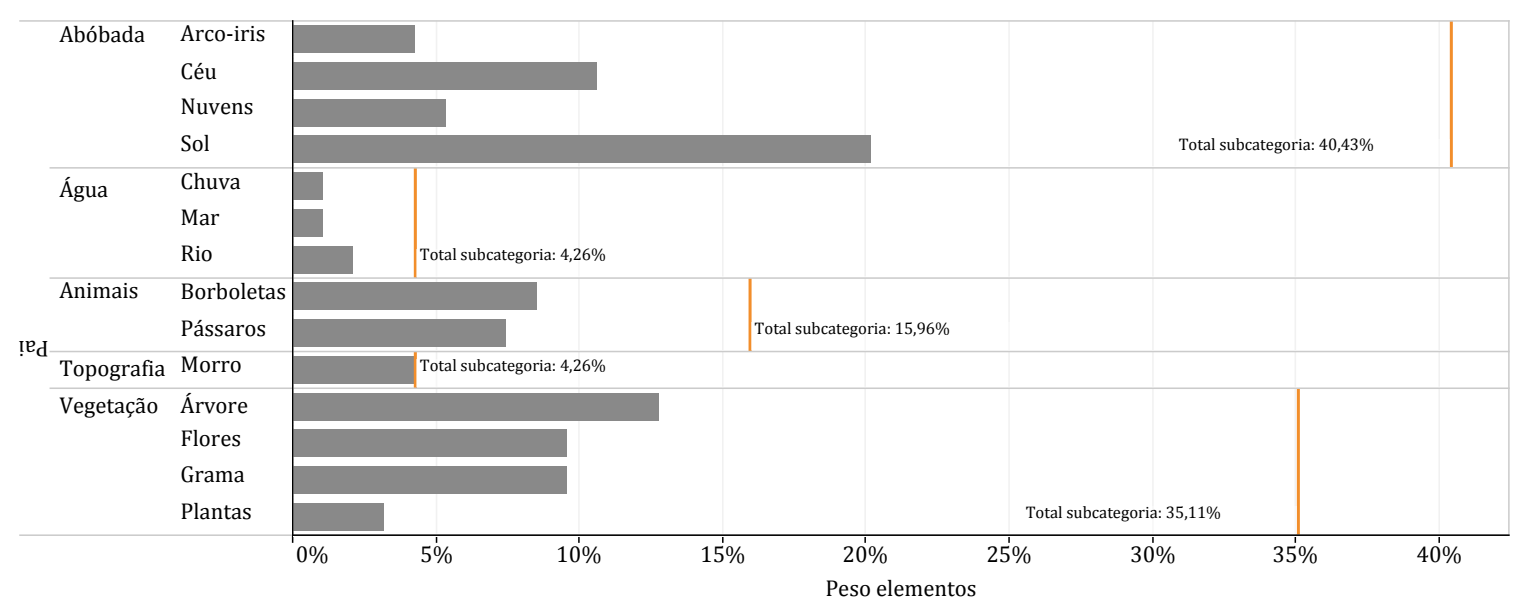

Figura 17 - Percentagem de elementos de cada categoria por participante

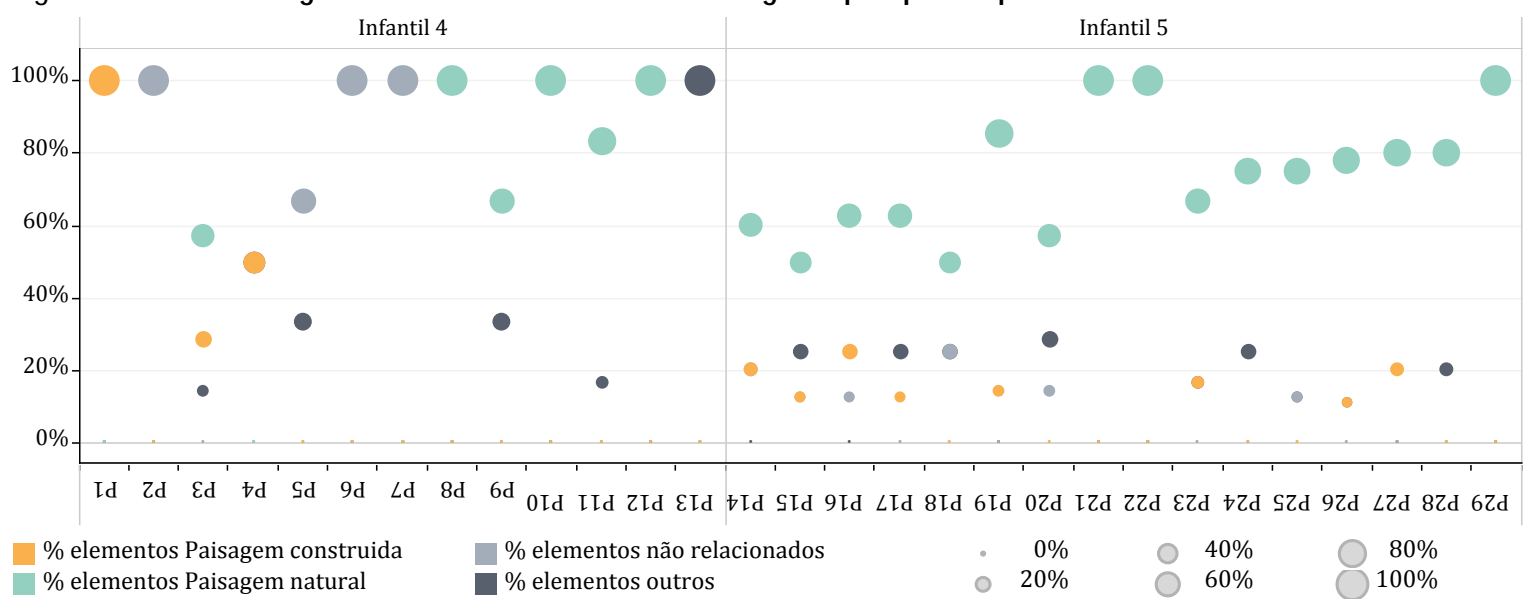

Figura 18 - Estimativa da preferência pelo tipo de paisagem

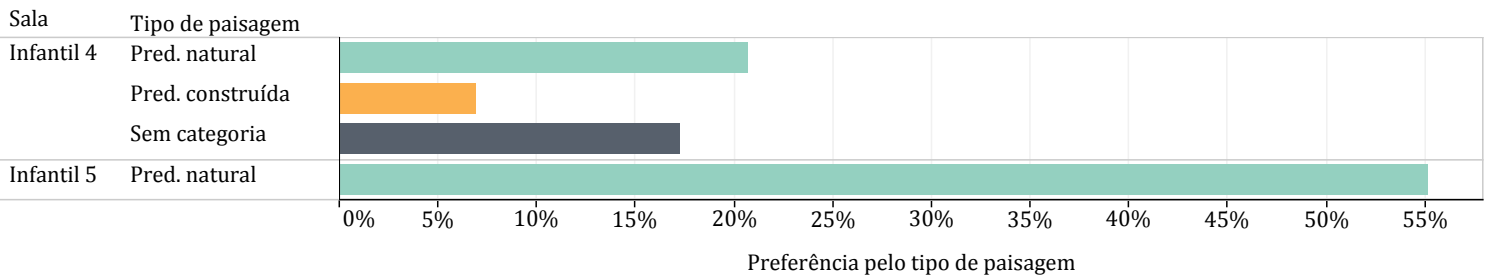

\section{Conclusões}

Este estudo permitiu identificar instrumentos e técnicas adequados para o levantamento das condições de uso e preferências do ambiente luminoso de crianças entre 4 e 6 anos de idade. Com relação aos métodos usados nesta pesquisa, são destacados os seguintes aspectos: (a) foi identificado que o registro fotográfico usando a função time-lapse em sessões de 15 min e com intervalo entre fotos de $5 \mathrm{~s}$ foi excessivo devido às poucas variações na localização e nas posições das crianças;

(b) embora o levantamento dos modelos de ocupação e níveis de iluminância tenham 
possibilitado a comparação das duas variáveis, os levantamentos fotométricos deste estudo não refletem de forma precisa as condições reais da iluminação do ambiente devido ao fato de a malha de pontos usada para a disposição dos data logger ter ficado restrita à localização das mesas usadas pelas crianças;

(c) como as crianças reconheceram sua sala nas imagens apresentadas durante a entrevista, foi mais fácil direcionar a atenção delas à questão de interesse. Dessa forma, destaca-se a importância de usar fotografias dos ambientes que serão avaliados pelas crianças;

(d) uma desvantagem desta abordagem metodológica é o processamento da informação. Para se chegar em dados suscetíveis de ser tratados estatisticamente, a demanda de tempo é alta, pois a maior parte do processamento da informação (ver as imagens, identificar a localização das crianças, estimar a área usada, quantificar as áreas, montar as imagens e processar a informação quantitativa) deve ser realizada de forma manual e por meio de diferentes tipos de programas; e

(e) a abordagem multimétodos utilizada neste estudo permitiu levantar os modelos de uso e ocupação das salas de aula durante as atividades, uso da iluminação artificial, uso das cortinas e preferências das crianças, se mostrando efetiva na aproximação das crianças e seu ambiente, conforme indicado na literatura.

As crianças que participaram das atividades manifestaram sua opinião sobre as condições de iluminação da sala em termos de "clara" ou "escura”, associando as características da iluminação com as tarefas ou atividades que realizavam. As diferenças na preferência pelo uso da iluminação artificial (na sala Infantil 4 as lâmpadas estiveram sempre desligadas, enquanto na sala Infantil 5 as lâmpadas foram ligadas durante algumas atividades) podem ser devido a:

(a) tipo de atividades realizadas segundo a sala: no caso da sala Infantil 4 as atividades realizadas durante o período observado foram mais flexíveis e sem plano de trabalho definido, enquanto na sala Infantil 5 houve atividades de "caderno”, nas quais as crianças precisaram de maior exigência visual;

(b) disponibilidade da luz natural, que, no período das atividades (vespertino), foi maior na sala Infantil 4; e/ou

(c) a percepção dos níveis de iluminância, que, mesmo sendo adequados na sala Infantil 5, conforme o recomendado na NBR ISO/CIE 89951 (ABNT, 2013), foram percebidos como insuficientes, demandando o uso da iluminação artificial. Isso confirma que, muitas vezes, adequados níveis de iluminância não necessariamente se traduzem em ambientes luminosos preferidos.

Por meio dos desenhos foi identificada a preferência das crianças de ambas as salas por elementos da paisagem natural, conforme demonstrado nos estudos realizados com adultos em diversos ambientes (ARIES; VEITCH; NEWSHAM, 2010; BENFIELD et al., 2013; BEUTE; DE KORT, 2013; CHANG; CHEN, 2005; GEUN et al., 2011; MATSUOKA, 2010; TUAYCHAROEN; TREGENZA, 2005). Dentro desta categoria, os elementos da abóbada celeste foram os mais desenhados. Quando classificados os desenhos em "Predominantemente natural", "Predominantemente construída" ou "Sem categoria”, na sala de Infantil 4 houve desenhos nas três classes, enquanto na sala Infantil 5 todos os desenhos refletiram preferência por paisagens mais naturais.

As informações sobre o tipo de céu podem ser úteis aos estudos relativos ao ofuscamento, se consideradas as abordagens mais recentes das pesquisas no tema, as quais tentam envolver alguns parâmetros subjetivos. No caso das crianças em salas de aula, este estudo apresenta algumas informações veladas sobre o efeito das características do céu em seu estado de ânimo. Ao ser visto através da janela um tipo de céu que produza sensações de bem-estar, a tolerância ao brilho tal vez seja influenciada por esse parâmetro subjetivo. No caso do céu limpo, céu de maior preferência pelos participantes deste estudo e condição sob a qual há maior probabilidade de ter radiação solar nas superfícies internas, a preferência (derivada de diversos motivos) poderia ser um fator de mitigação no cálculo da probabilidade de ofuscamento, como indicado por alguns autores (BEUTE; DE KORT, 2013; GEUN et al., 2011; TUAYCHAROEN; TREGENZA, 2007).

Este estudo permitiu identificar a tendência pelo uso do centro das salas, o qual poderia ser adotado como critério para o projeto de iluminação natural nas salas de educação infantil, priorizando como estratégia de iluminação natural as aberturas zenitais, considerada a latitude local, e a não incidência da radiação solar direta. Foi possível identificar como as crianças podem ser mais ativas no uso do ambiente em termos das configurações do sistema de iluminação quando são perguntadas pela preferência na posição das cortinas ou no uso da iluminação artificial.

Por último, este estudo permitiu refletir acerca da arquitetura das salas de aula de educação infantil e da participação que as crianças têm em sua configuração e formas de uso. 


\section{Referências}

ARIES, M. B. C.; VEITCH, J. A.; NEWSHAM, G. R. Windows, View, and Office Characteristics Predict Physical and Psychological Discomfort. Journal of Environmental Psychology, v. 30, n. 4, p. 533-541, dez. 2010.

\section{ASSOCIAÇÃO BRASILEIRA DE NORMAS} TÉCNICAS. NBR- ISO/CIE 8995-1: iluminação de ambientes de trabalho: parte 1: Interior. Rio de Janeiro, 2013.

BARRETT, P. et al. The Impact of Classroom Design on Pupils' Learning: final results ofaholistic, multi-level analysis. Building and Environment, v. 89, p. 118-133, 2015.

BARRETT, P. et al. The Holistic Impact of Classroom Spaces on Learning in Specific Subjects. Environment and Behavior, v. 49, n. 4, p. 425-451, 2017.

BARRETT, P.; BARRETT, L. The Potential of Positive Places: senses, brain and spaces. Intelligent Buildings International, v. 2, n. 3, p. 218-228, jul. 2010.

BENFIELD, J. A. et al. Classrooms With Nature Views: evidence of differing student perceptions and behaviors. Environment and Behavior, v. 47, n. 2, p. 140-157, 2013.

BERNARDI, N.; KOWALTOWSKI, D. C. C. K. Environmental Comfort in School Buildings: a case study of awareness and participation of users. Environment and Behavior, v. 38, n. 2, p. 155172, 2006.

BEUTE, F.; DE KORT, Y. A. W. Let the Sun Shine! Measuring explicit and implicit preference for environments differing in naturalness, weather type and brightness. Journal of Environmental Psychology, v. 36, p. 162-178, dez. 2013.

BLUYSSEN, P. M. Health, Comfort and Performance of Children in Classrooms: new directions for research. Indoor and Built Environment, v. 26, n. 8, p. 1040-1050, 2017.

BORGERS, N.; HOX, J.; SIKKEL, D. Response Quality in Survey Research With Children and Adolescents: the effect of labeled response options and vague quantifiers. International Journal of Public Opinion Research, v. 15, n. 1, p. 83-94, mar. 2003.

BORGERS, N.; LEEUW, E.; HOX, J. Children as Respondentes in Survey Research: cognitive development an responde quality. Bulletin de Méthodologie Sociologique, v. 66, p. 60-75, 2000.
CHANG, C.-Y.; CHEN, P.-K. Human Response to Window Views and Indoor Plants in the Workplace. HortScience, v. 40, n. 5, p. 13541359, 2005.

COLLINS, B. L. Review of the Psychological Reaction to Windows. Lighting Research \& Technology, v. 8, n. 2, p. 80-88, jun. 1976.

CRUZ, S. H. V. Ouvir Crianças: uma tarefa complexa e necessária. In: CRUZ, S. H. V. Ouvindo Crianças na Escola: abordagens qualitativas e desafios metodológicos para a psicologia. São Paulo: Casa do Psicólogo, 2010.

FABBRI, K. Thermal Comfort Evaluation in Kindergarten: PMV and PPD measurement through datalogger and questionnaire. Building and Environment, v. 68, p. 202-214, out. 2013.

GEUN, Y. Y. et al. Influence of Window Views on the Subjective Evaluation of Discomfort Glare. Indoor and Built Environment, v. 20, n. 1, p. 6574, fev. 2011.

GIRALDO, V. N. et al. Testing a Method to Assess the Thermal Sensation and Preference of Children in Kindergartens. In: RAWAL, R.; MANU, S.; KHADPEKAR, N. (Eds.). INTERNATIONAL PLEA CONFERENCE, 30., 2014. Proceedings... 2014.

HESCHONG MAHONE GROUP. Windows and Classrooms: a study of student performance and the indoor environment. Sacramento, 2003.

MARKOPOULOS, P. et al. Observation Methods. In: MARKOPOULOS, P. et al. Evaluating Children's Interactive Products: principles and practices for interaction designers. New York: Elsevier Science, 2008a.

MARKOPOULOS, P. et al. Survey methods 13. In: MARKOPOULOS, P. et al. Evaluating Children's Interactive Products: principles and practices for interaction designers. New York: Elsevier Science, 2008b.

MATSUOKA, R. H. Student Performance and High School Landscapes: examining the links. Landscape and Urban Planning, v. 97, n. 4, p. 273-282, 2010.

MORROW, V. Using Qualitative Methods to Elicit Young People's Perspectives on Their Environments: some ideas for community health initiatives. Health Education Research, v. 16, n. 3, p. 255-268, 2001. 
PINHEIRO, J. Q.; ELALI, G. A.; FERNANDES, O. S. Observando a Interação Pessoa-Ambiente: vestígios ambientais e mapeamento comportamental. In: PINHEIRO, J. Q.; ELALI, G. A.; FERNANDES, O. S. Métodos de Pesquisa nos Estudos Pessoa-Ambiente. São Paulo: Casa do Psicólogo, 2008.

SAYWITZ, K. J. et al. Developing Rapport With Children in Forensic Interviews: systematic review of experimental research. Behavioral Sciences \& The Law, v. 33, n. 4, p. 372-389, ago. 2015.

SAYWITZ, K. J.; CAMPARO, L. B. Interviewing Children: a primer. In: MELTON, G. B. et al. (Eds.). The SAGE Handbook of Child Research. Thousand Oaks: Sage, 2013.

SAYWITZ, K. J.; LARSON, R. P.; GOODMAN, G. S. Interviewing Children. In: MYERS, J. E. B. (Ed.). The APSAC Handbook on Child

Maltreatment. Thousand Oaks: Sage, 2011.

SOMMER, B.; SOMMER, R. Behavioral Maps. 2001. Disponível em:

<http://psychology.ucdavis.edu/sommerb/sommer demo/mapping/behmap.htm>. Acesso em: 15 set. 2017.

SOUZA, M. P. R. de. Apresentação. In: SOUZA, M. P. R. de. Ouvindo Crianças na Escola: abordagens qualitativas e desafios metodológicos para a psicologia. São Paulo: Casa do Psicólogo, 2010.
STEWART, D. M. Attitudes of School Children to Daylight and Fenestration. Building and Environment, v. 16, n. 4, p. 267-277, 1981.

TANNER, C. K. Effects of School Design on Student Outcomes. Journal of Educational Administration, v. 47, n. 3, p. 381-399, 2009.

TUAYCHAROEN, N.; TREGENZA, P. R. Discomfort Glare From Interesting Images. Lighting Research and Technology, v. 37, n. 4, p. 329-341, dez. 2005.

TUAYCHAROEN, N.; TREGENZA, P. R. R. P. View and Discomfort Glare From Windows.

Lighting Research and Technology, v. 39, n. 2, p. 185-200, jun. 2007.

VÁSQUEZ, N. G.; RUPP, R. F.; DÍAZ, L. A. Testing a Method to Assess the Thermal Sensation and Preference of Children in Kindergartens. In: RAWAL, R.; MANU, S.; KHADPEKAR, N. (Eds.). International PLEA Conference, 30., 2014. Proceedings... 2014.

\section{Agradecimentos}

Agradecemos à coordenação, às professoras e às crianças do Colégio Logosófico González Pecotche, unidade de Florianópolis, pelo apoio e acolhida durante a realização do experimento. Agradecemos à CAPES, pela bolsa de pósgraduação, e ao CNPq, pelo apoio financeiro.

Natalia Giraldo Vásquez

Programa de Pós-Graduação em Engenharia Civil | Universidade Federal de Santa Catarina | Trindade | Florianópolis - SC - Brasil | Caixa Postal 476 | CEP 88040-900 | Tel.: (48) 3721-4974 | E-mail: ngiraldv@gmail.com

\section{Fernando Oscar Ruttkay Pereira}

Programa de Pós-Graduação em Engenharia Civil e Programa de Pós-Graduação em Arquitetura | Universidade Federal de Santa Catarina | Tel.: (48) 3721-7080 | E-mail: ruttkay.pereira@ufsc.br

\section{Ariane Kuhnen}

Departamento de Psicologia, Centro de Filosofia e Ciências Humanas | Universidade Federal de Santa Catarina | Campus Universitário, Trindade | Florianópolis - SC - Brasil | CEP 88010-970 | Tel.: (48) 3721-8574 | E-mail: ariane.kuhnen@ufsc.br

Revista Ambiente Construído

Associação Nacional de Tecnologia do Ambiente Construído

Av. Osvaldo Aranha, 99 - 3o andar, Centro

Porto Alegre - RS - Brasil

CEP 90035-190

Telefone: +55 (51) 3308-4084

Fax: +55 (51) 3308-4054

www. seer. ufrgs. br/ ambienteconstruido

E-mail: ambienteconstruido@ufrgs.br 